\title{
Numerical Analysis to Investigate the Effects of the Design and Installation of Equilibrium Tension Plate Lysimeters on Leachate Volume
}

\author{
J. Mertens, * G. F. Barkle, and R. Stenger
}

\begin{abstract}
The composition and quantity of leachate as it moves down through the vadose zone is seldom measured directly because sampling in this unsaturated zone at the depths required has proven to be extremely difficult. A promising technique is the use of large porous plates known as equilibrium tension plate lysimeters (ETPLs), which have a controlled suction exerted on them that mimics the soil matric potential measured in the surrounding undisturbed soil profile. In the design phase for the installation of 15 ETPLs at five different depths (three replicates) around a central access chamber in the vadose zone in the Lake Taupo catchment of New Zealand, questions arose regarding the effects of the design and installation layout of the ETPLs on the measured leachate fluxes. To investigate the important design criteria and the spacing of the ETPLs, a numerical investigation using the HYDRUS-2D software was conducted. This analysis showed that the distance between the tension plate and the base (lower boundary) of the ETPL needs to be large enough to ensure that the effect of the dry zone (rain shadow effect) created below the ETPL on the soil zone being sampled above the plate is minimized. The boundary condition between the ETPL and the central access chamber was also shown to be critical, requiring a free-drainage condition in this location. The sampling efficiency of the ETPLs increases when the horizontal distance between adjacent ETPLs increases. Less obvious was the result that the sampling efficiency decreases with increasing vertical distance. This work demonstrates that the design and installation configuration of the ETPLs can significantly impact sampling efficiency. The relationships demonstrated in this work must be recognized and implemented in the design process, particularly when multiple ETPLs are installed at various depths through the vadose zone at other locations.
\end{abstract}

$\mathrm{M}$ UCH EFFORT has recently been put into developing rigorous and defensible in situ measurement techniques capable of determining the quantity and quality of leachate draining from the active root zone (Brye et al., 1999; Goyne et al., 2000; Gee et al., 2002; Zhu et al., 2002; Lentz and Kincaid, 2003; Siemens et al., 2003; Foley et al., 2003; Barzegar et al., 2004; Kosugi and Katsuyama, 2004; Masarik et al., 2004). In most situations, the zone beneath the plant roots is unsaturated and this places significant constraints on the type of measurement devices that are suitable for sampling in this zone. The most promising technique has been the development of in situ tension plate lysimeters, which use relatively large ceramic or sintered stainless-

J. Mertens and R. Stenger, Lincoln Environmental, Ruakura Research Centre, Private Bag 3062, Hamilton, New Zealand. G.F. Barkle, Aqualinc Research Limited, P.O. Box 14-041, Enderley, Hamilton, New Zealand. Received 14 Nov. 2004. *Corresponding author (mertensja@ yahoo.co.nz).

Published in Vadose Zone Journal 4:488-499 (2005).

Original Research Paper

doi:10.2136/vzj2004.0161

(c) Soil Science Society of America

677 S. Segoe Rd., Madison, WI 53711 USA steel porous plates. Various control options for the tension applied to these porous plates have been advocated. The simplest being zero tension, where no capacity to exert a tension on the plates exists. The zero-tension lysimeters rely on the formation of a saturated zone above the plate before water can be collected and sampled. The requirement of this saturated zone for sampling is an artifact of the measurement technique and is an unlikely condition to exist in most deep and reasonably drained soils (Brye et al., 1999). Additionally, the saturated area above the plate has been shown to cause divergent water flow away from the lysimeter and generally results in an underestimation of the natural water flux (Chiu and Shackelford, 2000). In a numerical evaluation by Flury et al. (1999), it was shown that the saturated zone not only has a large effect on the estimated leachate flux but it also influences the chemical concentration of the leachate sampled.

One of the most frequent control options is the constant tension plate lysimeter. Under these conditions the applied suction on the plate is fixed at a preselected value. This value is generally somewhere between -100 and $-300 \mathrm{~cm}$. As a result, the soil water conditions close to the sampler are a function of the applied suction possible, resulting in the sampled leachate being dissimilar to the soil water flux occurring under undisturbed conditions. Because the pore sizes from which water is sampled are related to the sampling suction applied, and recognizing that different concentrations of solute are known to exist in the differing pore sizes, the solute concentration that is sampled will depend on the applied constant suction (Rhoades and Oster, 1986; Kosugi and Katsuyama, 2004). To try and overcome these problems with fixed tension systems, confined lysimeter systems have been used that have side walls extending above the tension plates. The soil volume confined by the sidewalls reduces the influence of the applied constant suction on the undisturbed water flow through the top boundary (at the top of the sidewalls) of the sampler (Lentz and Kincaid, 2003). However, the sidewalls introduce the risk of saturation and preferential flow along the walls. Additionally, the walls make the installation of plates at depths in the profile more difficult.

In contrast to these more traditional methods, recent studies have recommended controlling the suction on the plate for extracting the soil water to be at the same tension as the soil matric pressure in the soil profile surrounding the tension plate (Brye et al., 1999, 2001; Siemens et al., 2003; Foley et al., 2003; Pelger et al., 2003; Lentz and Kincaid, 2003; Barzegar et al., 2004; Kosugi and Katsuyama, 2004). In these so called equilibrium-tension systems, the suction applied to the plate is either manually or automatically adjusted to the target 
value measured by tensiometers in the natural soil profile. This control strategy is expected to result in the rate of water extraction and the solute concentration sampled by the lysimeter to be representative of the unsaturated water flux in the undisturbed soil profile at the same depth. For further information on setup and control of ETPLs, the reader is referred to Masarik et al. (2004).

In a study on the impact of land use change on the groundwater and receiving surface waters in the Taupo catchment of New Zealand, there is a requirement to accurately measure the quantity and quality of the $\mathrm{C}$ and various $\mathrm{N}$ fluxes that are moving out of the root zone, through the vadose zone and beyond into the receiving groundwater. The chosen study site has a vadose zone which varies between 3.2 and $6.2 \mathrm{~m}$ in thickness depending on the changing depth to the saturated zone. Within this vadose zone, a maximum of 15 ETPLs ( 3 replicates at 5 depths) will be installed around the outside of a central access chamber. In the design phase of this sampling system questions arose regarding the effect of the design and configuration of the ETPLs on the sampled leachate. In particular, there were three key questions:

- What impact does the dry zone (rain-shadow) below the ETPL have on the sampled leachate?

- How important are the flow conditions between the central access chamber and the ETPL?

- What are the required separation distances (both vertically and horizontally) between ETPLs to maintain high sampling efficiencies?

The obvious strategy to explore these complex effects was to use a simulation tool to explore the relationships between installation configuration and predicted leachate volume measured by the ETPLs. As stated by Gee et al. (2002), the flow problem is multidimensional and any analytical treatment that neglects this multidimensionality may lead to errors from the simplification of the system. Gee et al. (2002) successfully applied the two-dimensional STOMP numerical model (White et al., 1995) to identify the importance of different design parameters and boundary conditions on the leachate sampled by a water fluxmeter with divergence control by comparing model predictions and measurements. Although a three-dimensional model is closer to reality, it is generally not cost-effective in terms of complexity and corresponding simulation time when investigating the importance of different design parameters and boundary conditions. However, it must be kept in mind that artifacts can be created by forcing a three-dimensional system to behave as if it were a two-dimensional computational solution. Therefore, quantitative results must be interpreted with care as discussed for each of the model setups described below. In this study, we chose the HYDRUS-2D software (Simunek et al., 1999), which has been used successfully in studies of a similar nature (Flury et al., 1999; Foley et al., 2003).

The objectives of this numerical exercise were to identify:
Table 1. Average soil hydraulic properties after Carsel and Parrish, 1988 for loamy sand, loam and clay loam and estimated soil hydraulic properties for the Taupo Ignimbrite soil type.

\begin{tabular}{llcccc}
\hline Soil & \multicolumn{1}{c}{$\theta_{\mathrm{r}}$} & $\theta_{\mathrm{s}}$ & $\boldsymbol{\alpha}$ & $n$ & $K_{\mathrm{s}}$ \\
\hline & $-\mathrm{cm}^{3} \mathrm{~cm}^{-3}-$ & $\mathrm{m}^{-1}$ & & $\mathrm{~m} \mathrm{~s}^{-1}$ \\
Loamy sand & $\mathbf{0 . 0 5 7}$ & $\mathbf{0 . 4 1}$ & $\mathbf{1 2 . 4}$ & $\mathbf{2 . 2 8}$ & $\mathbf{4 . 0 5 E - 0 5}$ \\
Loam & $\mathbf{0 . 0 7 8}$ & $\mathbf{0 . 4 3}$ & $\mathbf{3 . 6 0}$ & $\mathbf{1 . 5 6}$ & $\mathbf{2 . 8 9 E - 0 6}$ \\
Clay loam & $\mathbf{0 . 0 9 5}$ & $\mathbf{0 . 4 1}$ & $\mathbf{1 . 9 0}$ & $\mathbf{1 . 3 1}$ & $\mathbf{7 . 2 2 E - 0 7}$ \\
Ignimbrite & $\mathbf{0 . 0 0 0 5}$ & $\mathbf{0 . 6 7}$ & $\mathbf{7 . 0 1}$ & $\mathbf{1 . 4 3}$ & $\mathbf{2 . 8 4 E - 0 5}$ \\
\hline
\end{tabular}

- the distance needed between the plate and the base of the ETPL to minimize the effect of the dry zone below the ETPL base on the sampled leachate volume

- the most suitable boundary condition (no-flow, seepage face, or free-drainage) between the central access chamber and the ETPL

- the horizontal and vertical separation distances needed between ETPLs so that interference is minimized

Since the subsurface site conditions and vadose zone materials had not been investigated at this early design stage in our study, the simulations and investigations described in this work were applied to the wide range of subsurface conditions that could possibly exist at the site. This range of soil types was also used to investigate the sensitivity of the results to different vadose zone materials and to demonstrate how installation and design options can significantly affect the measurements of leachate volumes and concentrations in the vadose zone.

\section{MODEL SETUP}

The HYDRUS-2D model (Simunek et al., 1999) solves the Richards' equation (Richards, 1931) for twodimensional vertical flow using the van Genuchten (1980)-Mualem (1976) soil hydraulic functions. In the initial simulations, a uniform soil profile was assumed over the total depth. Approximate averages of the soil hydraulic parameters (the saturated hydraulic conductivity, $K_{\mathrm{s}}$; the saturated, $\theta_{\mathrm{s}}$, and residual, $\theta_{\mathrm{r}}$, water contents $\left[\mathrm{L}^{3} \mathrm{~L}^{-3}\right]$; and the shape parameters, $\alpha\left[\mathrm{L}^{-1}\right]$ and $n$ ) were obtained from Carsel and Parrish (1988) for three different soil types: sandy loam, loam, and clay loam (Table 1). The modeled flow domain is presented in Fig. 1 and similar to the flow domain used by Foley et al. (2003). The upper atmospheric boundary condition uses daily rainfall data for 2003 measured close to Taupo. Evapotranspiration was initially set to zero to exclude the effect of root water uptake on the flow pattern. The lower boundary is assumed to be a freedrainage boundary type, and both sides of the flow domain are set up as no-flow boundaries. The ETPL is located $1 \mathrm{~m}$ below the soil surface and has a width of $30 \mathrm{~cm}$ and a length of $75 \mathrm{~cm}$, as shown in Fig. 2. Note that the ETPL as shown in Fig. 2 will be inserted into a stainless-steel "shoebox" with a removable top. Once the ETPL is inserted into the shoebox, the top of the stainless-steel box will be removed and the ETPL jacked upward to ensure good contact between the plate and soil, making use of slurry. The jack will thereafter be 


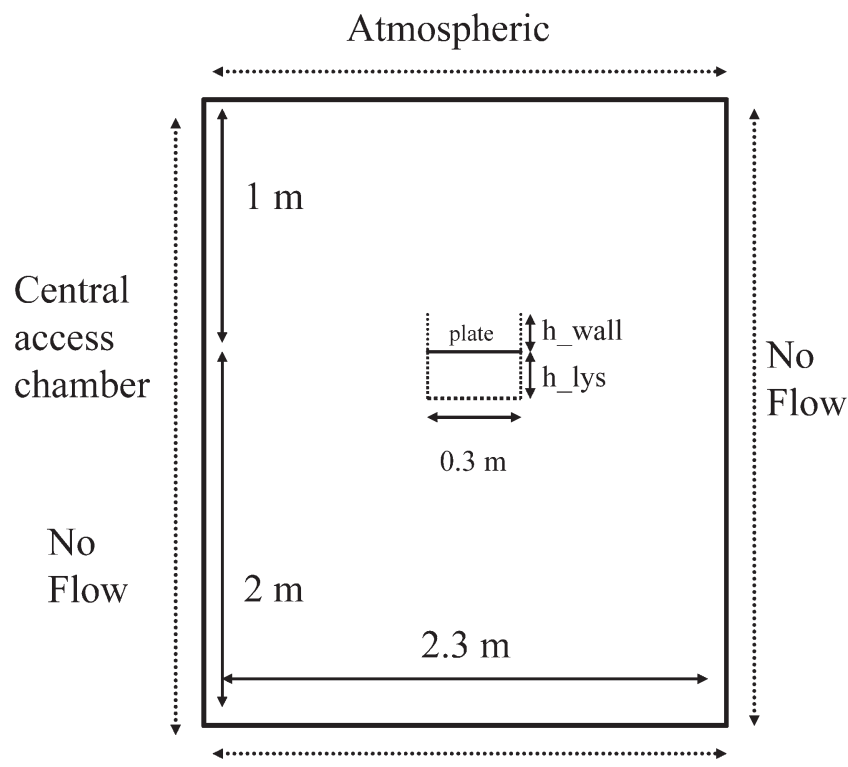

Free drainage

Fig. 1. Modeled flow domain (vertical cut) and boundary conditions (h_wall = height of the wall, h_lys = height of ETPL).

replaced by packers to ensure permanent hydraulic contact between plate and soil. The height of the lysimeter (h_lys) is defined as the distance between the tension plate and the base of the ETPL and hence equals the sum of the reservoir height and cavity height as shown in Fig. 2. Since both the reservoir and packers are inside the metal shoebox, this boundary is modeled as a noflow boundary and its height varied to investigate the interaction between this distance and the simulated leachate flux through the plate. The walls of the ETPL are set up as no-flow boundaries having a width of $1 \mathrm{~cm}$ and varying height (h_wall). Initial soil tensions are set to $-100-\mathrm{cm}$ matric head potential for the entire domain. As model output, the water-balance errors are checked and the simulated cumulative leachate volume sampled by the tension plate are compared for different configurations against the undisturbed soil water flux at the same depth. The finite element mesh was generated using the triangulation tool of the MSEHGEN-2D imbedded in the HYDRUS-2D software. The mesh was refined in the neighborhood of internal boundaries around the ETPLs. Initial simulations showed that results differ very minimally ( $0.3 \%$ of annual leachate volume) when increasing the number of nodes from 500 to 2000 for the setup presented in Fig. 1. Throughout the study, the number of calculation nodes was therefore varied between 700 and 2000 depending on the complexity of the problem and the size of the internal boundaries (e.g., height of the lysimeter and walls). Water-balance errors were lower than $0.1 \%$ in all simulations reported below.

The modeling of an ETPL requires two simulations. The first one without the ETPL has an observation node, inserted in the model domain at the location where the tension plate will be located. This node records the matric head potential that occurs in the undisturbed soil profile throughout the simulation. This recorded time series of tensions is subsequently applied

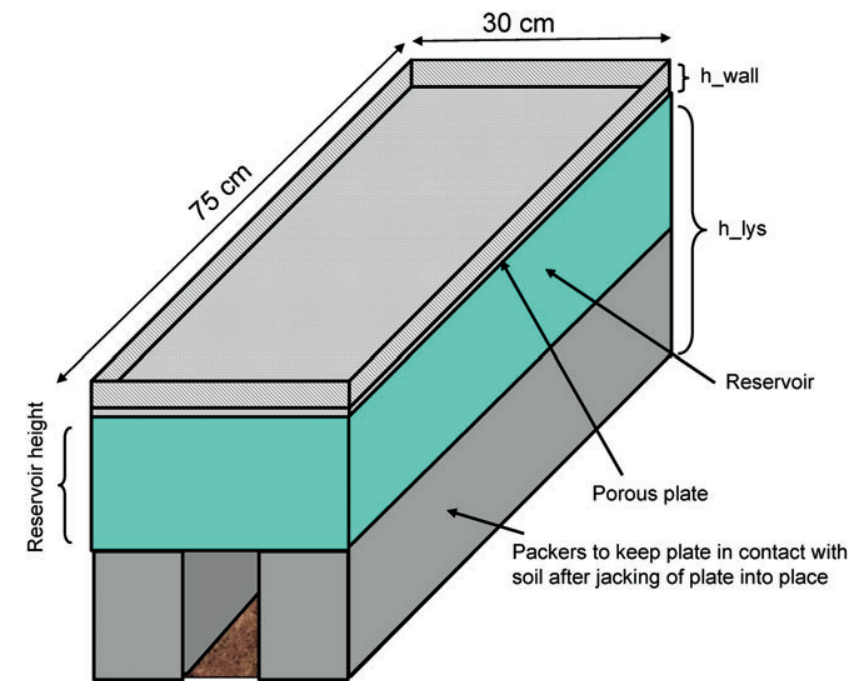

Fig. 2. Schematic diagram of a single ETPL. Note that the metal shoebox in which the ETPL is inserted is not shown in the picture.

in the second simulation to the tension plate modeled in the ETPL, as a variable head boundary condition to simulate the leachate volume collected by the ETPL.

\section{RESULTS AND DISCUSSION}

Initial simulations were conducted to explore our expectation that for a properly working ETPL, inserting vertical walls does not affect the sampled leachate volume since the tension plate is in constant equilibrium with the surrounding soil tension. At the same time, we investigated the effect walls have on leachate volumes sampled using constant tension lysimeters. For each of the soil types investigated, a constant tension of -100 and $-300 \mathrm{~cm}$ was applied to the plate. The height of the lysimeter (h_lys) was assumed to be $50 \mathrm{~cm}$ and the height of the wall (h_wall) was set to 0,15 , and $50 \mathrm{~cm}$, respectively. The simulated leachate volume was normalized so that a normalized cumulative leachate volume of one corresponds to the cumulative volume that passes through an ETPL without walls. Figure 3 shows the result of this analysis for the three soil types considered. As also reported by Foley et al. (2003), increasing the height of the wall of constant tension plates leads to a reduction in normalized cumulative leachate flux for all soil types and applied tensions. Figure 3 confirms the expectation that walls do not influence leachate volumes sampled by ETPLs. Therefore, in what follows, ETPLs are modeled without walls unless explicitly mentioned otherwise.

\section{Effect of Distance between Tension Plate and Base of the ETPL}

The ETPL's reservoir should be large enough so it can retain the volume of drained water between sampling times, but at the same time should not be too large to create problems in installation and ensuring that the structural integrity of the central access chamber can be maintained. The effect of increasing the lysimeter height (which is defined as the ETPL's reservoir height 


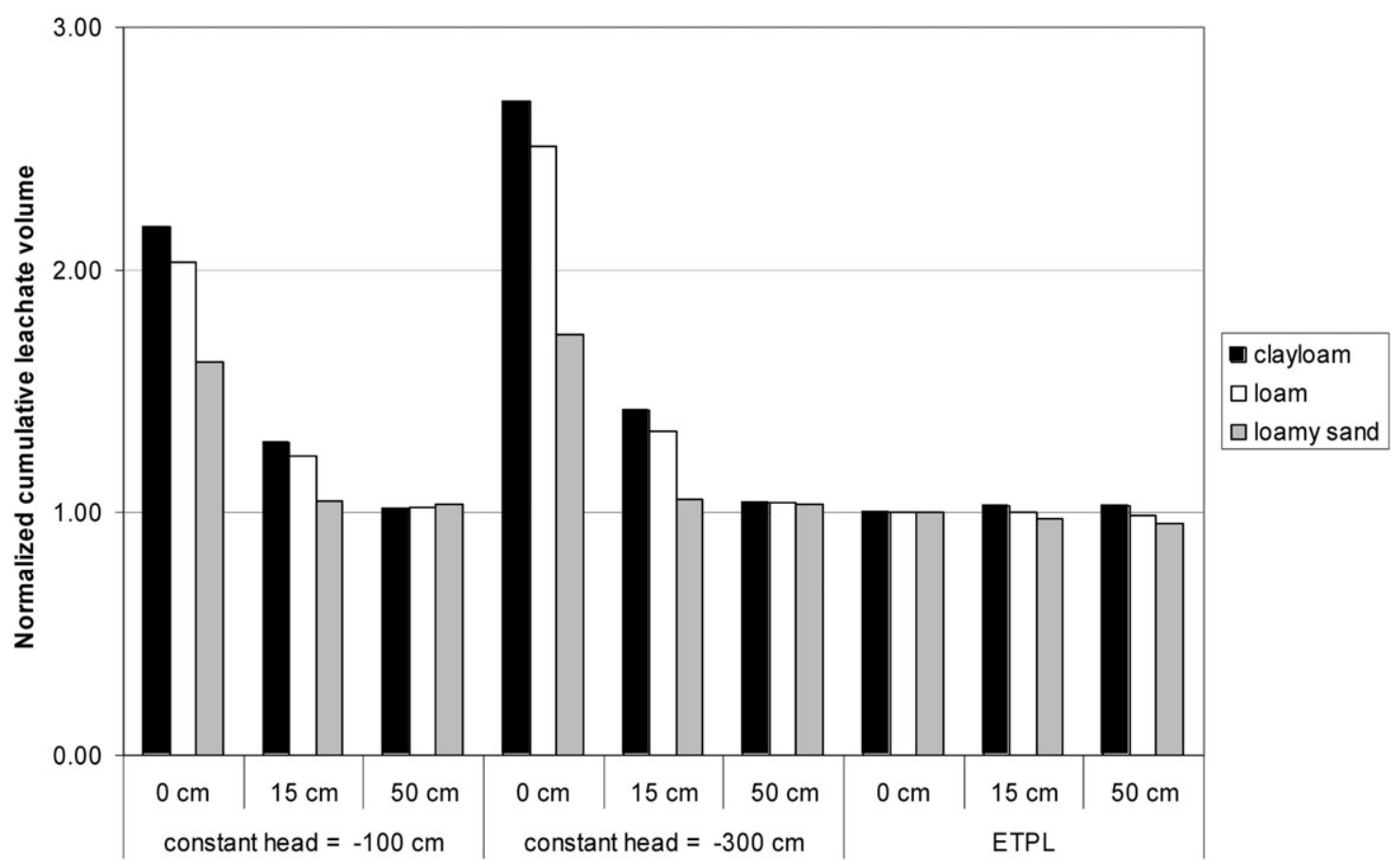

Fig. 3. Effect of lysimeter wall height on cumulative normalized leachate volumes for three different soil types (clay loam, loam, and loamy sand), two applied constant heads $(-100$ and $-300 \mathrm{~cm})$, and an ETPL.

plus the ETPL's cavity height, h_lys) on the normalized cumulative leachate for a 12 -mo period is presented in Fig. 4 for the three soil types considered. The simulated leachate volume collected by the tension plate is normalized using the leachate volume as simulated by a tension plate with a $100-\mathrm{cm}$ distance above the base of the ETPL $\left(\mathrm{h} \_\right.$lys $\left.=100 \mathrm{~cm}\right)$. Figure 4 shows that for distances $<100 \mathrm{~cm}$, lower cumulative leachate volumes are predicted than this reference volume, and the reduction is greatest for the clay loam soil. Due to the asymptotic nature of the results in Fig. 4, it could be concluded that the reference volume is close to the leachate volume that would occur under undisturbed soil conditions. The explanation for the effect of increasing leachate volumes with increasing lysimeter height was found by investigating the distribution of the soil water content and soil water flow pattern around the ETPL, which is shown in Fig. 5 for the loamy soil. This shows what could be called an "umbrella" effect. The soil below the ETPL remains drier than the surrounding soil since it is shaded from the infiltrating water because of the ETPL removing this water from the profile. For lower lysimeter heights, this effect is propagated to the zone above the plate and causes water to diverge away from the tension plate and move into the drier area under the lysimeter, as clearly indicated by the flow arrows in the top right of Fig. 5. Increasing lysimeter height increases the distance from the top of the plate to the dry soil zone below the base of the ETPL and therefore increases the flow through the tension plate. As indicated in Fig. 4, the umbrella effect is greater for the finer clay loam than for the loam, while the umbrella effect is negligible for the coarser loamy sand.
We found no reference to this effect in previous literature discussing ETPL; however, these results show that the umbrella effect can play a significant role in the volume of leachate collected. Therefore, in the design phase, the distance between the tension plate and the bottom of the ETPL must be chosen such that the potential error is minimized for the given soil texture. The two-dimensional model suggests that a distance of $50 \mathrm{~cm}$ is sufficient to capture between 98.5 and $100 \%$ of the reference volume depending on the soil type.

The flow pattern for this type of problem is approximately two-dimensional because the plate is $75 \mathrm{~cm}$ long in the third dimension. Flow in the third dimension is likely to occur only at the edges of the ETPL and does not influence the flow pattern significantly. For all further simulations described below, the ETPL's height (h_lys) is set at $50 \mathrm{~cm}$.

\section{Effect of Boundary Condition between Central Access Chamber and the ETPL}

Figure 6 illustrates the boundary condition between the central access chamber and the ETPL, which is described as the "inner-boundary condition." The distance between the central access chamber and the closest end of the plate is $50 \mathrm{~cm}$, and the length of the plate is assumed to be $75 \mathrm{~cm}$. Three different inner-boundary conditions were considered:

1. Free drainage. This can be obtained by backfilling the access hole with the same soil material that was dug out of the hole, taking care that a similar bulk density is obtained. In reality, whether or not a real free-drainage condition is obtained after backfilling will depend on the backfilling process. 


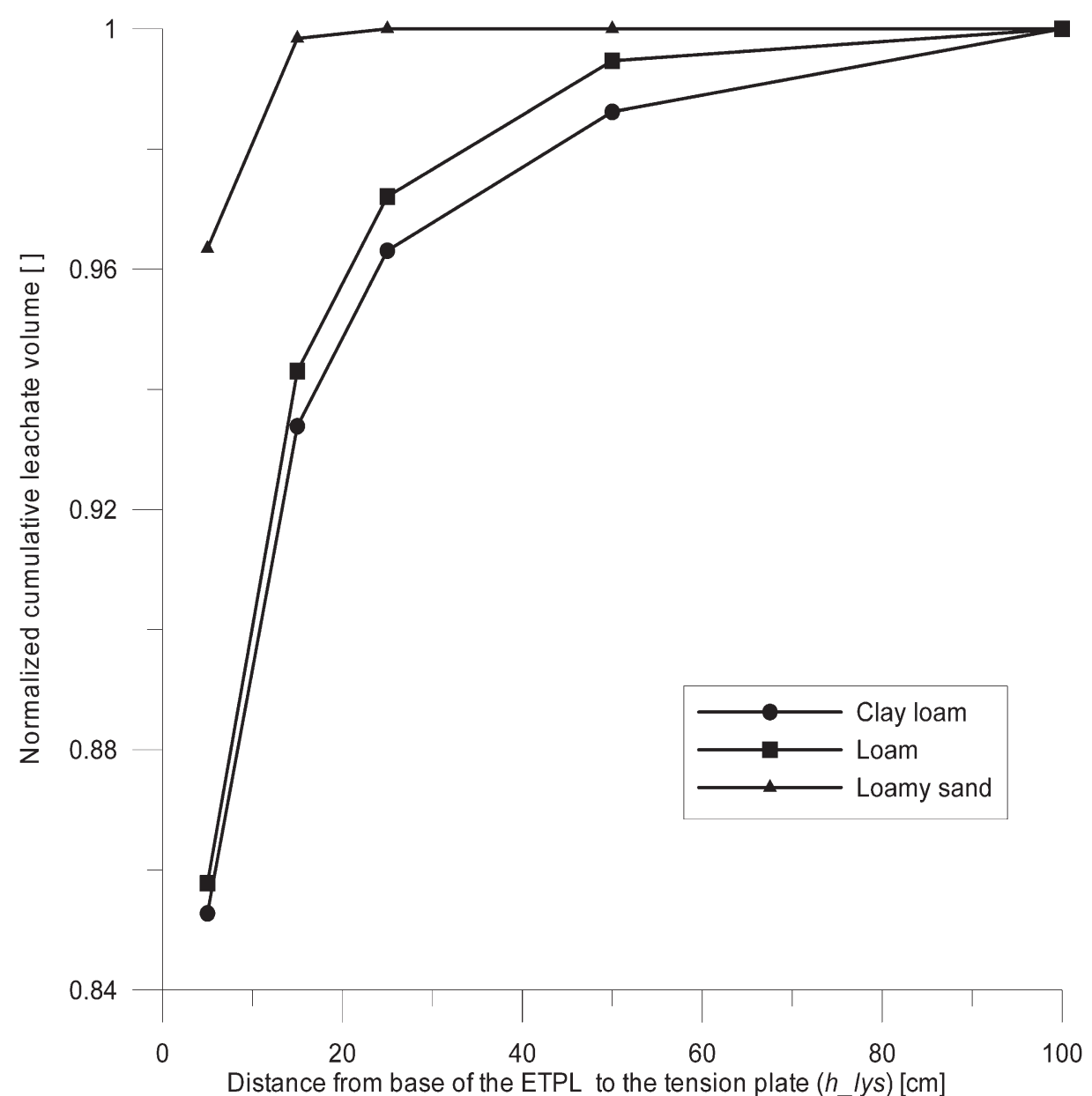

Fig. 4. Effect of distance between tension plate and base of the ETPL (= lysimeter height or $h$ _lys) on normalized cumulative sampled leachate volume for three different soil types (clay loam, loam, and loamy sand).

It is easy to imagine that hydraulic properties could change due to structural differences before and after the backfilling operation. Another option to obtain this condition is by installing a second equilibrium tension plate over the whole length of the cavity between central access chamber and the recording ETPL and removing the drained water out of the system. This has the advantage that the ETPL remains easily accessible from the central access chamber, but it is expensive.

2. No-flow boundary. This can be obtained by inserting and supporting a stainless-steel plate at the top of the cavity. This has the advantage that no backfilling is needed and the ETPL remains easily accessible from the access chamber.

3. Seepage face. This can be obtained by installing a drain at the top of the inner-boundary (Fig. 6) and allowing the water that reaches this boundary to be drained and removed from the system.

Both the no-flow and seepage face inner-boundary conditions have the advantages that the ETPL remains easily accessible from the central access chamber and that backfilling or the installation of a second plate is not required. To investigate the effect of these three options on the sampled leachate volume, a HYDRUS-2D model of this system was developed. This model also allowed the option of investigating whether vertical lysimeter walls above the plate could help overcome any detrimental effects caused by this inner-boundary condition.

The predicted effects of the configuration of the inner-boundary condition (no-flow or seepage face) and lysimeter wall height on the cumulative normalized volume for the three different soil types is presented in Fig. 7. A normalized leachate volume of one represents the leachate volume that would drain through the natural undisturbed profile and therefore corresponds to a free-drainage inner-boundary condition. Figure 7 shows that imposing a no-flow inner-boundary condition results in the ETPL overestimating the leachate volume. Inserting walls was not successful in decreasing this effect except for the sandy loam soil type. This result is understandable because a no-flow boundary allows no water to leave the system in the region of the cavity. This results in saturated conditions building up in the region between the chamber and the ETPL, which causes water to converge to the ETPL.

Also shown in Fig. 7, but perhaps less obvious, is that imposing a seepage face at the top of the cavity by installing a drain still overestimates the simulated ETPL leachate volume when no walls are installed. Contrary 

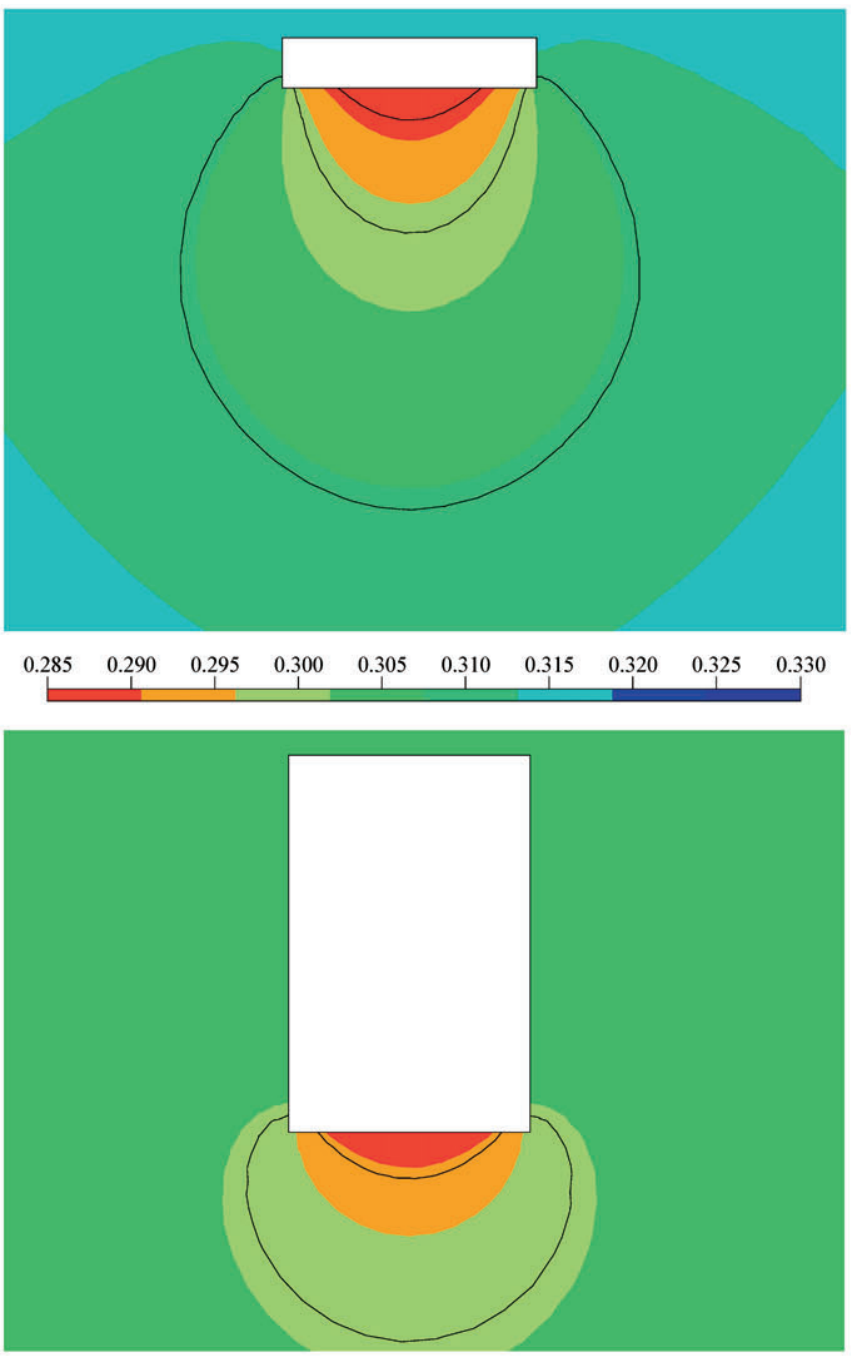

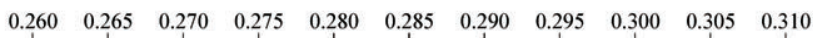

Fig. 5. Soil moisture content (\%, v/v) (left) and flow pattern (right) around an ETPL with a height (h_lys) of $5 \mathrm{~cm}$ (top) and $50 \mathrm{~cm}$ (bottom) in a loamy soil. (Note that velocity vectors are drawn at each finite element node. Therefore, the length of vectors represents flux and not density.)

to the no-flow boundary condition, installing walls does have a large effect on the leachate captured by the ETPL under this boundary condition. However, walls as high as $50 \mathrm{~cm}$ are needed to allow the ETPL to sample a representative leachate volumes for all soil types. However, a $50-\mathrm{cm}$ wall height is not considered feasible in field conditions because they would make the installation of the ETPL extremely difficult. Since saturated conditions are needed for water to flow through a seepage face, the same mechanism of saturation and converging flow to the ETPL as in the no-flow option causes this overestimation in the leachate volume. The reason that the $50-\mathrm{cm}$-high walls allow reasonable estimates of the leachate volume is that this wall height allows saturated conditions to build up at the inner boundary, which forces the water through the seepage face without interfering with the flow pattern to the ETPL. As shown by the flow pattern presented in Fig. 8, 15-cm-high walls do not suffice to prevent the convergent flow to the plate from occurring.

Special attention must be given here to the dimension- ality problem. The lack of the third dimension in this particular model domain is potentially a significant drawback. In the two-dimensional model, water reaching the inner boundary is either forced through the seepage face or forced to flow to the ETPL. In reality, however, this water can also flow in the third dimension (perpendicular to the model domain presented in Fig. 6) over the 30-cm-wide inner boundary. By using a twodimensional model, it is impossible to quantify the impact that the third dimension has on the predicted leachate volumes. Therefore, the results presented in Fig. 7 should be interpreted as indications of the importance of the inner-boundary effects rather than quantitatively being exact.

Since $50-\mathrm{cm}$ walls are not feasible, all simulations described below were conducted assuming that a freedrainage inner-boundary condition exists.

\section{Required Separation Distance between ETPLs}

Because it is our aim to install 15 ETPLs (3 replicates at 5 depths) around the outside of a central access cham- 
Atmospheric

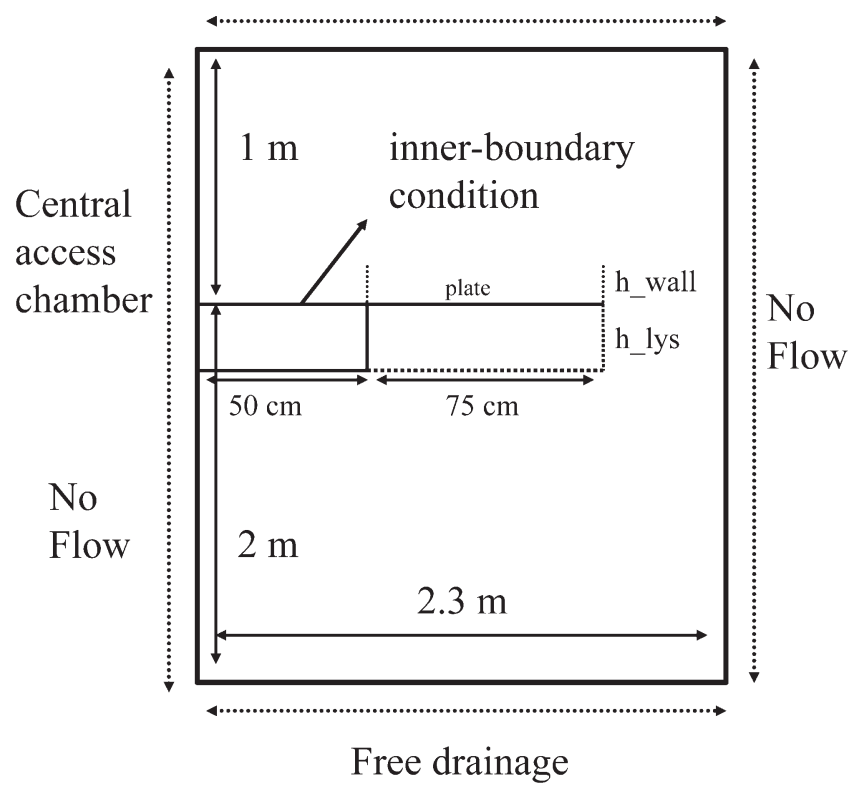

Fig. 6. Modeled flow domain and boundary conditions (h_wall $=$ height of the wall, $h \_l y s=$ height of ETPL); the boundary condition between the central access chamber and the ETPL is denoted as the inner boundary condition.

ber, the horizontal separation distance between ETPLs determines the required diameter for the access chamber. The horizontal separation distance between the ETPLs should be large enough so that their effect on the flow pattern and thus the sampled leachate volumes is minimal. On the other hand, increasing the horizontal

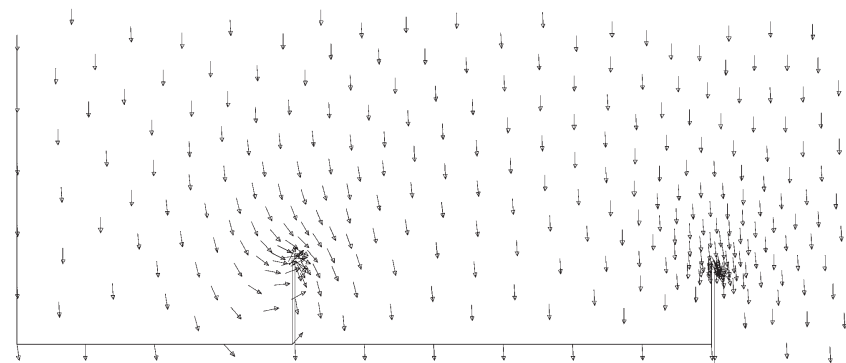

Fig. 8. Flow pattern around an ETPL with a height of $50 \mathrm{~cm}$ (h lys $=$ $50 \mathrm{~cm})$ in a loamy soil with a $15-\mathrm{cm}$ lysimeter wall $\left(\mathrm{h} \_l y s=15 \mathrm{~cm}\right)$ and a seepage-face inner boundary.

separation distance between ETPLs increases the required diameter of the central access chamber, which significantly increases the capital and installation costs. It was also questioned how neighboring ETPLs should be installed vertically. Is it better to install neighboring ETPLs closer together or further apart in the vertical dimension?

As presented in Fig. 9, the modeling exercise considered three offset distances in the horizontal direction (i.e., 0, 50, and $75 \mathrm{~cm}$ between ETPLs) and two vertical

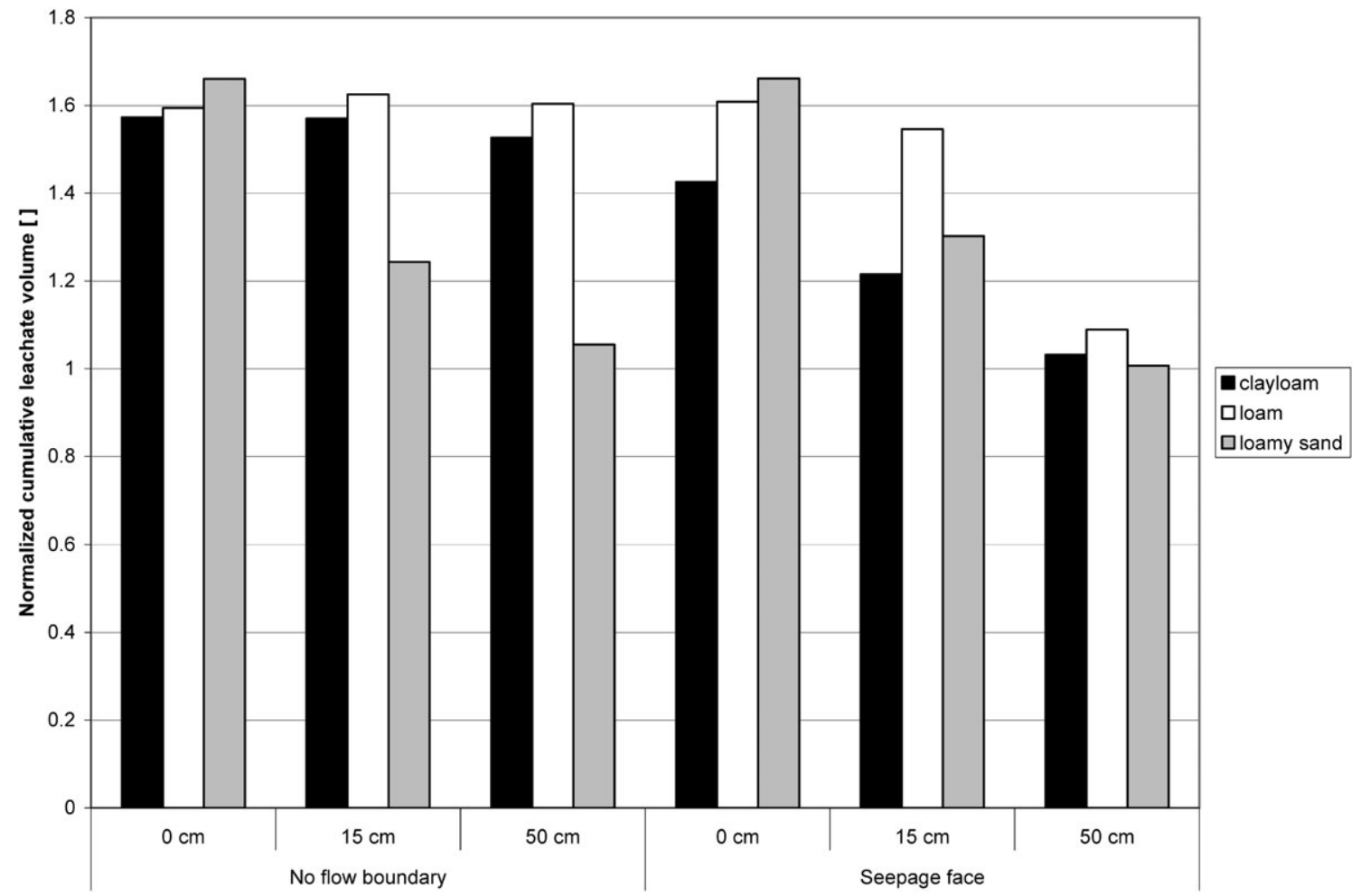

Fig. 7. Effect of inner boundary condition and lysimeter wall height on normalized cumulative leachate volume for three different soil types (clay loam, loam, and loamy sand). 


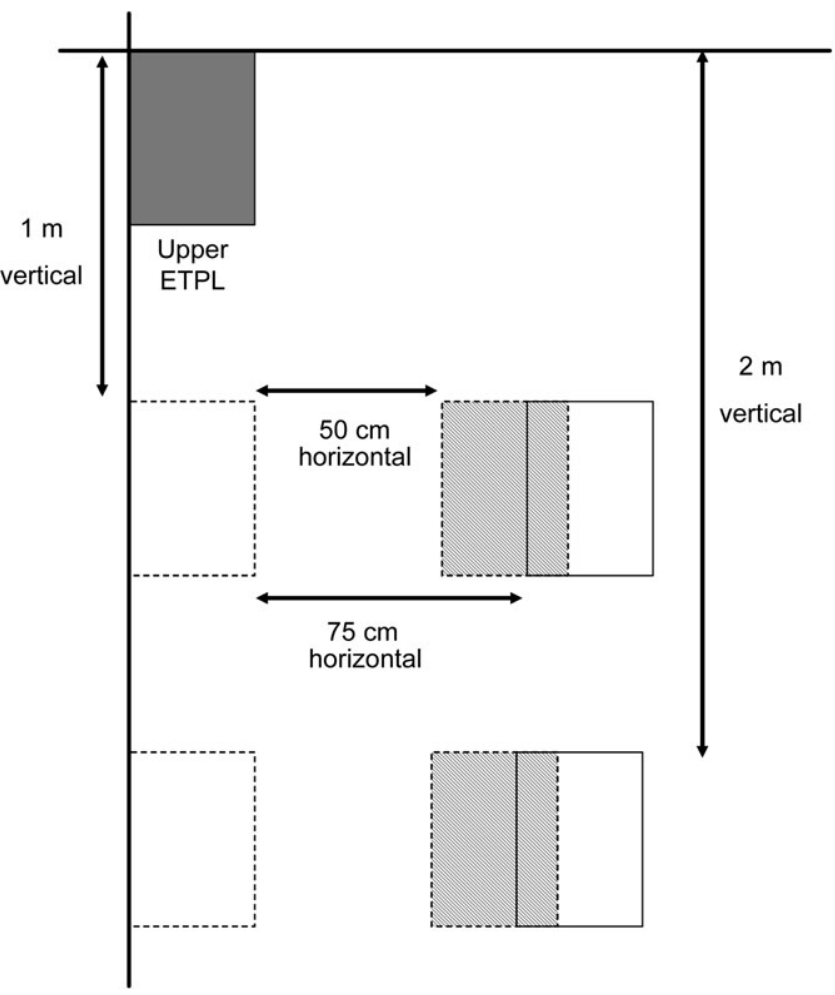

Fig. 9. Schematic showing the three horizontal separation distances: $0 \mathrm{~cm}$ (ETPLs below each other), $50 \mathrm{~cm}$, and $75 \mathrm{~cm}$ between ETPLs, and two vertical separation distances: 1 and $2 \mathrm{~m}$ between ETPLs used in the simulations.

separation distances ( 1 and $2 \mathrm{~m}$ between ETPLs). In addition to the three soil types used previously, an extra simulation was performed using the soil hydraulic properties of a Taupo ignimbrite soil. Since this soil type is relevant for the Taupo catchment only and we wanted to investigate the general importance of the umbrella and inner-boundary effects for different soil types, it was not used in the previous simulations. The soil hydraulic properties available for this soil type were laboratory measurements of saturated hydraulic conductivities and water retention curves performed on 11 undisturbed soil samples (Speir et al., 1988). The van Genuchten (1980)Mualem (1976) hydraulic functions were fitted to these measurements, and the geometric averages of the estimated parameters were used in the modeling exercise (Table 1). The normalized cumulative leachate volumes sampled by the lower ETPL for each of the horizontal $(0,50$, and $75 \mathrm{~cm})$ and vertical $(1$ and $2 \mathrm{~m})$ separation distances are presented in Fig. 10. A normalized cumulative leachate volume of one, or reference leachate, corresponds to the leachate sampled by a lower ETPL in the absence of the upper ETPL.

The results show that increasing the horizontal separation distance between ETPLs increases the normalized cumulative volume regardless of the vertical separation distance. If the ETPLs are installed without any horizontal separation and $1 \mathrm{~m}$ below each other, the predicted leachate is only between 60 and $78 \%$ of the reference leachate. If the ETPLs are installed directly below each other, it is best to install them vertically as far apart as possible. Increasing the vertical separation distance from 1 to $2 \mathrm{~m}$ increases the sampled predicted leachate to between 70 and $83 \%$ of the reference leachate, depending on the soil type. This is still low and suggests that a horizontal separation distance between ETPLs is required when there is a requirement to sample leachate volumes that are as close as possible to the actual undisturbed leachate volumes.

Less obvious is that increasing the vertical separation distance between ETPLs does not increase the predicted leachate volume when a horizontal separation distance of 50 or $75 \mathrm{~cm}$ is used. When using these horizontal separation distances, independent of soil texture, it is better to put the ETPLs closer together vertically than further apart. This is explained by the growing zone of influence of the dry umbrella effect with depth as shown in Fig. 11. From the bottom of the ETPL, the umbrella effect shows a bulb-like shape, indicating that its horizontal zone of influence increases with depth before contracting again. Therefore, it is more likely that with 50- or 75-cm horizontal separation distances, the ETPL $1 \mathrm{~m}$ below is less influenced by the umbrella effect from the ETPL above than if it were $2 \mathrm{~m}$ below. Sampling efficiencies are generally lower for finer soils because it is in these soils that the umbrella effect is greater, as shown in Fig. 4. Therefore, larger horizontal separation distances are required in fine-textured soils compared with coarser soils. The two-dimensional model shows that a horizontal separation of $75 \mathrm{~cm}$ and a vertical separation distance of $1 \mathrm{~m}$ yield the best results and allow for leachate volumes between 94 and $100 \%$ of the reference leachate, depending on the soil texture. Similar to the investigation of the separation distance between the tension plate and the bottom of the ETPL, the flow pattern for this type of problem is close to twodimensional, and flow in the third dimension is likely to occur only at the edges of the plate.

\section{Taupo Profile Simulation}

The modeling analysis presented above demonstrates the impact that the design and layout of the ETPL can have on the predicted leachate volumes measured in these devices. The layout of the ETPL and their separation distances that will be used in the Taupo installation were based on the results of these modeling analyses. It was shown that the ETPL must have a height of 50 $\mathrm{cm}$ to minimize the rain shadow effect. A free-drainage inner-boundary condition was shown to be necessary, which requires backfilling of the gap between ETPL and the central chamber. Lysimeter walls are not required. A horizontal separation distance of $75 \mathrm{~cm}$ between ETPLs will be used. This layout results in a diameter of the central access chamber of $4 \mathrm{~m}$. The modeling showed that vertical separation distances between neighboring ETPLs must be kept as small as possible. Based on soil and vadose zone investigations with the identification of the soil horizons and geologic layers at depth, it was concluded that ETPLs should be installed at depths of $40,150,260,400$, and $520 \mathrm{~cm}$ from the soil surface.

To estimate the cumulative effect that installing five ETPLs may have on the sampling efficiencies, a full 

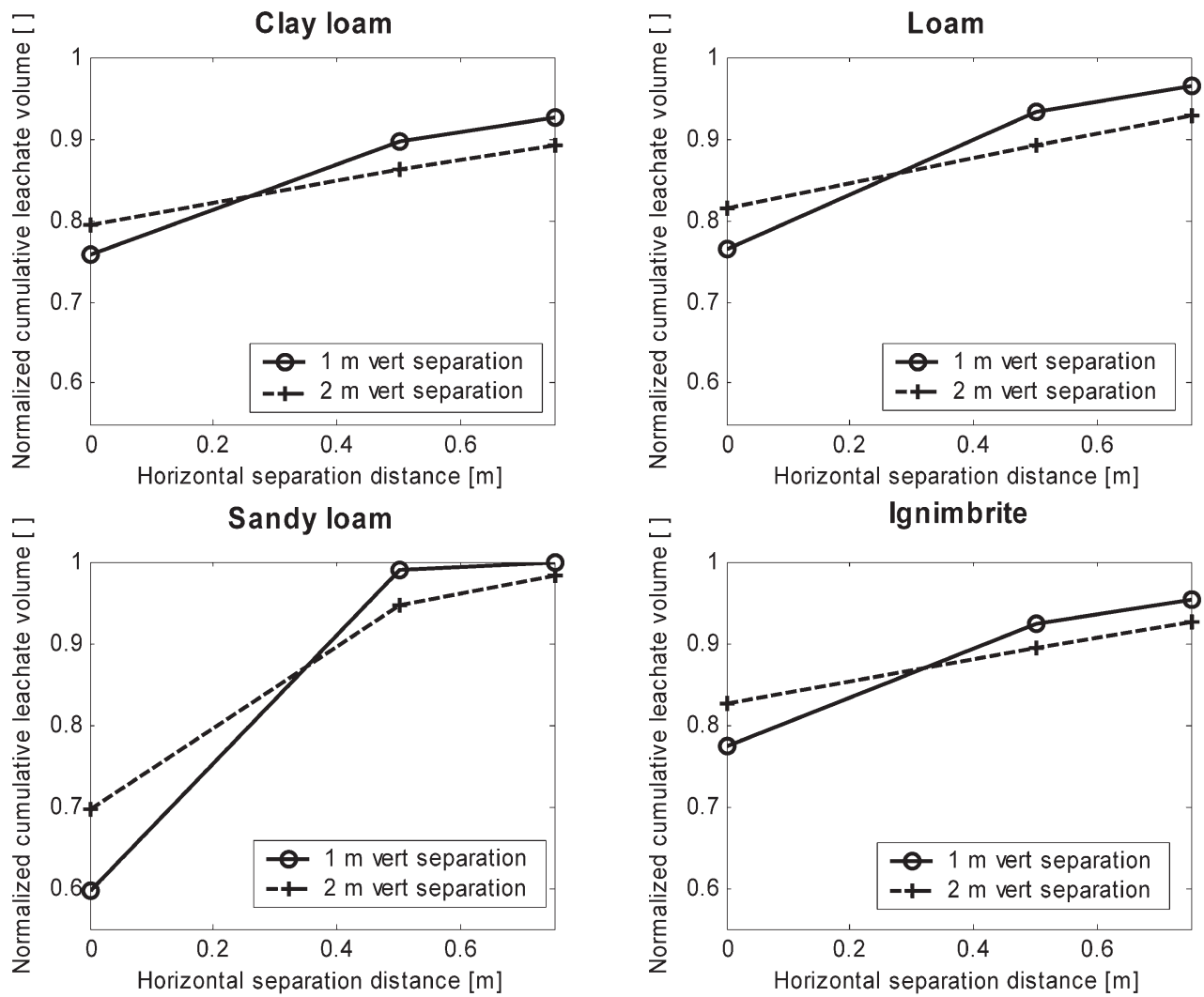

Fig. 10. Effect of horizontal and vertical separation distance on the normalized cumulative leachate volume sampled by the lower ETPL for four different soil types (clay loam, loam, sandy loam, and ignimbrite).

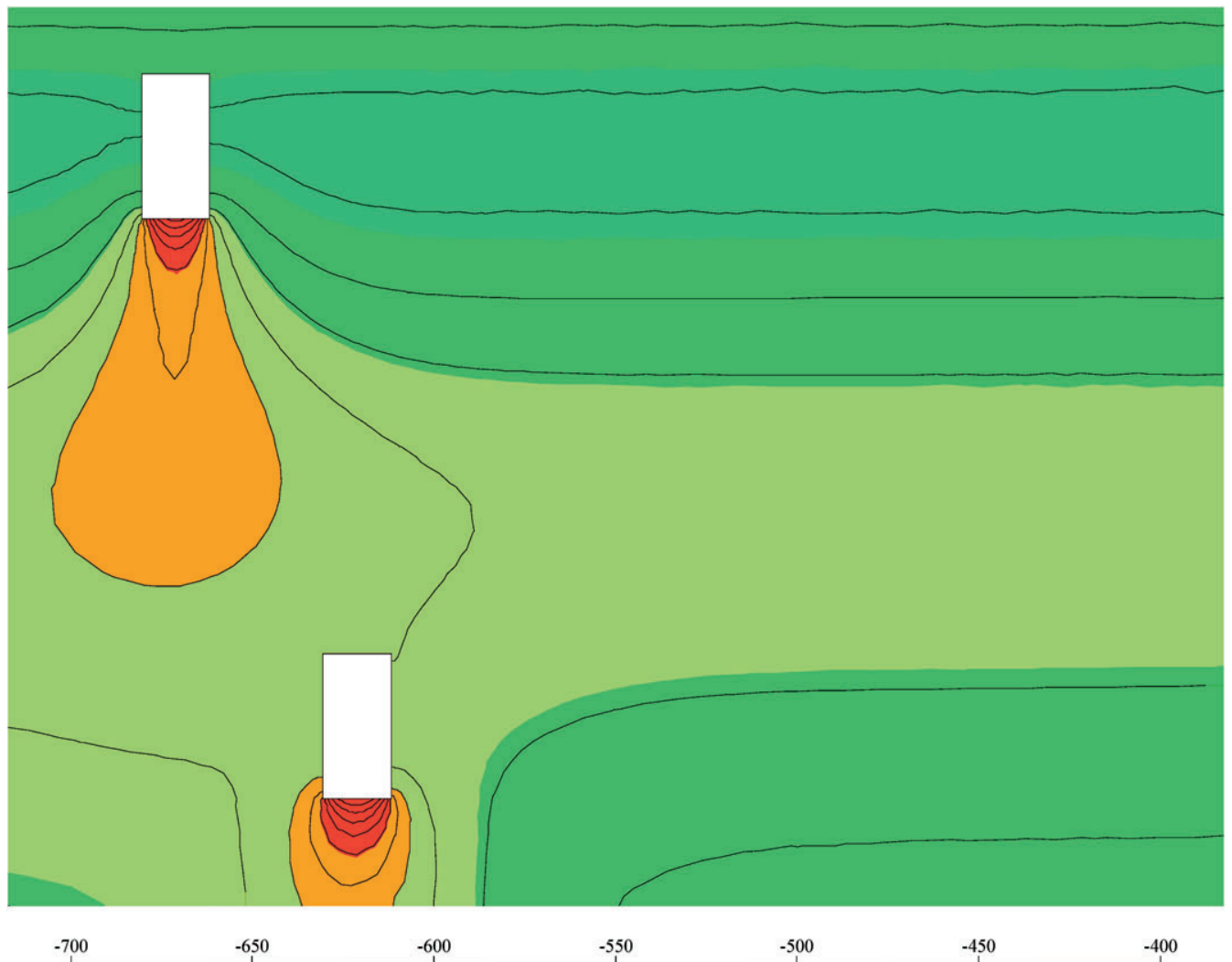

Fig. 11. Soil tension profile (millimeters) around two ETPLs with a horizontal separation of $50 \mathrm{~cm}$ and a vertical separation of $200 \mathrm{~cm}$ in a loamy soil. 


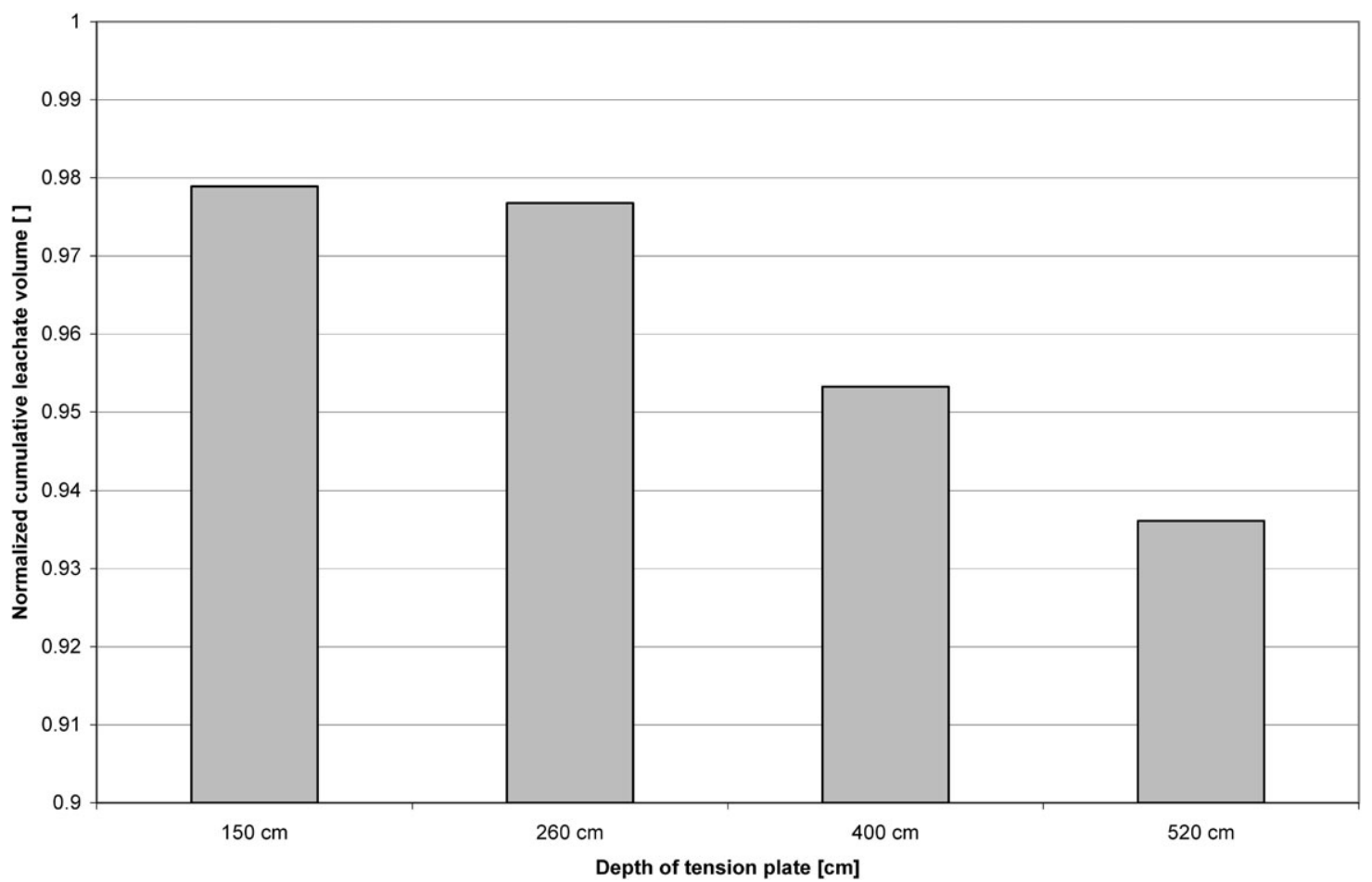

Fig. 12. Normalized cumulative leachate volumes captured by four ETPLs installed at different depths in the Taupo profile.

Taupo domain model, $7 \mathrm{~m}$ deep and $6 \mathrm{~m}$ wide, was developed, including the five ETPLs at their respective depths. The soil used was the Taupo ignimbrite throughout the profile, except for a clay loam horizon from 4.35to $6.07 \mathrm{~m}$ deep, which represents a palaeosol layer found at this depth. Because the full model was set up to provide an estimation of what the likely soil tensions at the ETPL surfaces would be and the ETPL sampling efficiencies that could be expected in the field, evapotranspiration was also considered in the model. Predicted soil tensions through the profile ensured that the physical characteristics (air entry value and conductivity) of the porous plate would be matched to in situ conditions likely to occur in the actual installation. Water extraction was described using the Feddes et al. (1978) function, and the root water extraction parameters were taken from the internal HYDRUS-2D database for a grass having a $30-\mathrm{cm}$ root zone. As the bottom boundary condition for the model, a fixed tension of $0 \mathrm{~cm}$ (or saturated condition) throughout the year was used, which corresponds to a fixed water table depth at $7 \mathrm{~m}$. We know, however, that the water table fluctuates throughout the year and will therefore continuously monitor its level. In future simulations, it will be possible to insert a variable head bottom boundary condition representing the water table dynamics throughout the year. The normalized cumulative leachate volumes for each of the four lower ETPLs are presented in Fig. 12. A normalized cumulative leachate volume of one corresponds to the simulated sampled leachate by the tension plate at that depth in the absence of any other ETPLs. The chosen layout of the individual ETPLs in combination with the separation distances between them results in a sampling efficiency between 93.7 and
$97.9 \%$ of the reference leachate depending on the depth of the ETPL.

These reported efficiencies have to be interpreted with care because they are based on simulations using nonsite soil hydraulic parameters and not based on in situ measurements or laboratory measurements on sitespecific samples. However, even if site-specific hydraulic properties were available, care would still have to be taken interpreting the results of simulations using only measured parameters. It has been shown that soil hydraulic parameters derived from laboratory and/or in situ measurements may differ significantly from the parameters required by the model to simulate field observations (Mertens et al., 2005). We therefore do not claim that the efficiencies of our ETPLs will be exactly as reported; however, we believe that similar efficiencies will be achieved.

Additionally, fast pathways (root channels, wormholes, cracks) that exist in field soils potentially affect the flow patterns and therefore the collected leachate volumes. However, in this study, the effect of preferential flow paths on the collected leachate volumes is expected to be low. The ignimbrite is rather coarse material and will not produce cracks due to wetting and drying cycles. No deep rooting systems are present because the site has been under pasture for more than 40 yr. Preferential flow is not expected to be an important process deeper in the profile because of the lack of biological activity. Therefore, fast flow paths are only likely to exist in the top soil and potentially influence leachate volumes collected by the upper ETPLs at the $40-\mathrm{cm}$ depth. It must therefore be kept in mind that simulated volumes (only matrix flow considered) potentially underestimate the leachate volumes. Although the 
importance of the process is hard to estimate before the experiment, its possible effect must be recognized and accounted for in the design of the collection vessel.

\section{SUMMARY AND CONCLUSIONS}

This modeling exercise was performed during the design phase for the installation of 15 ETPLs at multiple depths throughout the vadose zone in the Lake Taupo catchment of New Zealand. The study investigated numerically how the layout of one or more ETPL affects the sampled leachate volume for different soil textures. The numerical investigation shows that the distance between the tension plate and the base of the ETPL should be large enough to minimize the impact of the dry zone (rain shadow) occurring below the ETPL on the soil tensions existing at the sampling plate, and hence the predicted leachate volume. Larger lysimeter heights are required in finer than for coarser soil textures; for a clay loam a lysimeter height of $50 \mathrm{~cm}$ is sufficient. However, even for coarser soil textures, the reservoir height must be designed so that it can retain the volume of leachate collected in between automatic or manual sampling times. Initial ETPL construction based only on the texture in which they were first installed may compromise their use in later experiments if they need to be installed in finer-textured soil.

The modeling shows that the inner-boundary condition in the region between the ETPL and the central access chamber is extremely important. It can be demonstrated that acceptable leachate volumes can be achieved by installing vertical walls on an ETPL with an inner no-seepage boundary condition. However, the required wall height makes this option infeasible for all soil textures. Therefore, it must be concluded that a free-drainage boundary condition is required in this location. A free-drainage boundary is difficult to accomplish, but could be achieved by either backfilling with the vadose zone material removed, taking care to pack the soil to the same undisturbed bulk density, or by installing a second ETPL and removing the water from the system. The latter has the advantage that the ETPL is easily accessible for maintenance, but significantly increases the capital and installation costs.

Since 15 ETPLs ( 3 replicates at 5 depths) are to be installed around the outside of a central access chamber, the horizontal separation distance between ETPLs determines the dimension of this central access chamber. This requires a proper balance between the reduction in sampling efficiency due to interference when ETPLs are close together and the installation and capital costs incurred with a larger-diameter central access chamber. Results show that the sampling efficiency increases when the horizontal distance between ETPLs increases. Installing ETPLs directly below each other results in the lowest sampling efficiencies simulated, and a maximum vertical separation is preferred in this situation. Significant horizontal separation between ETPLs $(50 \mathrm{~cm}$ or more) is required to measure leachate volumes that represent the undisturbed situation. Minimal vertical separation distance is advantageous when a horizontal separation distance between ETPLs of 50 or $75 \mathrm{~cm}$ is used. A configuration of a horizontal separation distance of $75 \mathrm{~cm}$ and a vertical separation distance of 1 $\mathrm{m}$ yields sampling efficiencies between 94 and $100 \%$ of the reference leachate volume depending on the soil texture considered. On the basis of this analysis, we concluded that the ETPLs should be installed with a horizontal separation of $75 \mathrm{~cm}$ and a minimal vertical separation distances for the Taupo experiment. A horizontal separation of $75 \mathrm{~cm}$ results in a required diameter of the central access chamber of $4 \mathrm{~m}$.

To complete the simulations, a full model was set up to estimate the cumulative effect that installing five ETPLs has on the sampling efficiencies of individual ETPLs. The analysis shows that the chosen layout of the individual ETPLs (no lysimeter walls, 50-cm ETPL height, inner free-drainage boundary condition with the horizontal separation distances between ETPLs of 0.75 $\mathrm{m}$, and minimal vertical separation) results in sampling efficiencies between 93.7 and $97.9 \%$ of the reference leachate, depending on the location of the ETPL in the soil profile.

\section{ACKNOWLEDGMENTS}

We would like to thank the Foundation for Research Science and Technology (FRST) for funding this work as part of Lincoln Environmental Research's Groundwater Quality Protection Programme. We are grateful to Jan Vanderborght, Diederik Jacques, and Vince Bidwell for their useful comments and critical review.

\section{REFERENCES}

Barzegar, A.R., S.J. Herbert, A.M. Hashemi, and C.S. Hu. 2004. Passive pan sampler for vadose zone leachate collection. Soil Sci. Soc. Am. J. 68:744-749.

Brye, K.R., J.M. Norman, L.G. Bundy, and S.T. Gower. 1999. An equilibrium tension lysimeter for measuring drainage through soil. Soil Sci. Soc. Am. J. 63:536-543.

Brye, K.R., J.M. Norman, L.G. Bundy, and S.T. Gower. 2001. Nitrogen and carbon leaching in agroecosystems and their role in denitrification potential. J. Environ. Qual. 30:58-70.

Carsel, R.F., and R.S. Parrish. 1988. Developing joint probability distributions of soil-water retention characteristics. Water Resour. Res. 24:755-769.

Chiu, T.F., and C.D. Shackelford. 2000. Laboratory evaluation of sand under-drains. J. Geotech. Geoenviron. Eng. 126:990-1001.

Feddes, R.A., P.J. Kowalik, and H. Zaradny. 1978. Simulation of field water use and crop yield. John Wiley and Sons, New York.

Flury, M., M.V. Yates, and W.A. Jury. 1999. Numerical analysis of the effect of the lower boundary condition on solute transport in lysimeters. Soil Sci. Soc. Am. J. 63:1493-1499.

Foley, J., D. Rassam, and M. Silburn. 2003. Conceptual designs for lysimetry on swelling clay soils. Paper presented at International Soil Tillage Research Organisation (ISTRO) 16th Triennial Conference, Brisbane, Australia.

Gee, G.W., A.L. Ward, T.G. Caldwell, and J.C. Ritter. 2002. A vadose zone water fluxmeter with divergence control. Water Resour. Res. 38(8). doi:10.10129/2001WR000816.

Goyne, K.W., R.L. Day, and J. Chorover. 2000. Artifacts caused by collection of soil solution with passive capillary samplers. Soil Sci. Soc. Am. J. 64:1330-1336.

Kosugi, K., and M. Katsuyama. 2004. Controlled-suction period lysimeter for measuring vertical water flux and convective chemical fluxes. Soil Sci. Soc. Am. J. 68:371-382.

Lentz, D.R., and D.C. Kincaid. 2003. An automated extraction control system for soil water percolation samples. Soil Sci. Soc. Am. J. 67:100-106. 
Masarik, K.C., J.M. Norman, K.R. Brye, and J.M. Baker. 2004. Improvements to measuring water flux in the vadose zone. J. Environ. Qual. 33:1152-1158.

Mertens, J., H. Madsen, M. Kristensen, D. Jacques, and J. Feyen. 2005. Sensitivity of soil parameters in unsaturated zone modelling and the relation between effective, laboratory and in-situ estimates. Hydrol. Proc. 19:1611-1633.

Mualem, Y.1976. A new model predicting the hydraulic conductivity of unsaturated porous media. Water Resour. Res. 12:513-522.

Pelger, D., J. Foley, and M. Silburn. 2003. Design and construction of an equilibrium tension lysimeter for use in swelling clay soils. Paper presented at International Soil tillage Research Organisation (ISTRO) 16th Triennial Conference, Brisbane, Australia.

Rhoades, J.D., and J.D. Oster. 1986. Solute content. p. 985-1006. In A. Klute (ed.) Methods of soil analysis. Part 1.2nd ed. SSSA Book Ser. 5. SSSA, Madison, WI.

Richards, L.A. 1931. Capillary conduction of liquids through porous mediums. Physics 1:318-333.

Siemens, J., M. Haas, and M. Kaupenjohann. 2003. Dissolved organic matter induced denitrification in subsoils and aquifers? Geoderma 113:253-271.
Simunek, J., M. Sejna, and M.Th. van Genuchten. 1999. The HYDRUS-2D software package for simulating two-dimensional movement of water, heat and multiple solutes in variably saturated media. Version 2.0. IGWMC-TPS-53. Colorado School of Mines, Golden, CO.

Speir, T.W., P.B.S. Hart, R. Lee, W.C. Rijkse, and J.P.C. Watt. 1988. Ohaaki geothermal power development: Land suitability for spray irrigation with cooling tower condensate. Soil Bureau Contract Rep. 88/15. Department of Scientific and Industrial Research, Lower Hutt, NZ.

van Genuchten, M.Th. 1980. A closed-form equation for predicting the hydraulic conductivity of unsaturated soils. Soil Sci. Soc. Am. J. 44:892-898.

White, M.D., M. Oostrom, and R.J. Lenhard. 1995. Modeling fluid flow and transport in variably saturated porous media with the STOMP simulator. 1. Nonvolatile three-phase model description. Adv. Water Res. 18:353-364.

Zhu, Y., R.H. Fox, and J.D. Toth. 2002. Leachate collection efficiency of zero-tension pan and passive capillary fiberglass wick lysimeters. Soil Sci. Soc. Am. J. 66:37-43. 